\title{
HUBUNGAN KETAHANAN PANGAN DAN \\ STABILITAS KEAMANAN NEGARA \\ (KRISIS PANGAN DI VENEZUELA)
}

Reni Arlyan

\begin{abstract}
Problem of Food emerged as a Non-Traditional Secuirty (NTS) issue in the aftermath of the Cold War and was identified as one of the seven pillars of human security by the 1994 UNDP Report 'New Dimensions' in Security. Food security as 'the means for all people at all times to have both physical and economic access to basic food' and that food security is an entitlement. When the shortages food supply in a country, it will be an increasing the conflict civil society, so the stability of the state security being disrupted. The availability of adequate food supplies could become the core of social contact in all the country's political system. The food crisis in Venezuela resulted in civil conflict be increased. Venezuela is the world's oil producing countries but due to falling world oil prices, then became distracted State reception system. The political system came along with the economic crisis makes Venezuela in the worst condition.This economic crisis makes Venezuela experienced a food crisis, so many societies suffered famine and looting food even do violence to gain access the food. Finally, the conflict civil society occur due to the food crisis and the stability of the State security becomes disrupted. In this paper using descriptive analysis method that describes the relationship of food security in Venezuela that can be disrupt the stability of State security.

In this paper, using the perspective of Food Securitization.This is based on a change in the subject of security not only on military issues but the extension of the concept security including the threat of food security within a country. Food can be utilized as a political weapon by states and can be characterized as a form and symbol of political power.
\end{abstract}

Keywords: Food Security, Conflict, Stability, Human Security, The Securitization of Food. 
Pendahuluan

Dewasa ini perkembangan isu dalam ilmu hubungan internasional telah mengalami pergeseran perspektif. Hadirnya fenomena baru dalam hubungan internasional telah menghadirkan ancaman-ancaman baru yang cenderung menciptakan ketidakstabilan politik dan ekonomi yang meluas baik, di negara maju maupun negara berkembang. Hadirnya ancaman-ancaman baru ini terus menggambarkan bahwa keamanan tidak dapat dibatasi lagi sebagai masalah tradisional dalam uapaya mempertahankan dan melindungi perbatasan nasional terhadap intervensi militer eksternal saja, tetapi juga mencakup ancaman keamanan non-tradisional (NTS). Ancaman-ancaman ini didefinisikan sebagai tantangan dalam upaya memelihara kelangsungan hidup dan kesejahteraan masyarakat yang muncul dari sumber nonmiliter seperti perubahan iklim, kelangkaan sumber daya, penyakit menular, bencana alam, migrasi tidak teratur, kekurangan makanan, perdagangan narkoba dan kejahatan transnasional. Masalah-masalah yang dikategorikan sebagai keamanan non-tradisional memang bukanlah hal yang baru, tetapi pemahaman lebih mendalam sebagai ancaman keamanan muncul di era pasca-Perang Dingin, ketika para pemimpin global menganggap kemanan bersifat multidimensi (Beeson \& Bisley, 2017).

Pergeseran perspektif ini memang lebih mengedepankan kemanan manusia/Human Security dalam suatu negara. Gagasan keamanan manusia/Human Security sendiri nampak 
jelas dari Human Report 1994 yang di gulirkan oleh United Nations Development Programme (UNDP memiliki aspek konsep utama yaitu Pertama, kemamanan dari ancaman yang bersifat kronis seperti kelaparan, penyakit dan penindasan. Dan Kedua, perlindungan dari gangguan yang bersifat mendadak dan menyakitkan dalam pola hidup sehari-hari baik di rumah, dilingkungan pekerjaan maupun didalam masyarakat'.Dan ringkas menjadi bagaimana keamanan manusia dapat didefenisikan menjadi 'Freedom from fear, Freedom from want and Freedom to live dignity' (UNDP, 1994:23). Keamanan manusia ini berarti melindungi kebebasan mendasar (melindungi manusia dari ancaman dan situasi yang kritis (parah) dan menyebar luas terhadap masyarakat serta bagaimana menciptakan sistem politik, sosial, lingkungan, ekonomi, militer, dan budaya yang stabil sehingga individuindividu dalam suatu negara dapat bertahan hidup).

Banyaknya literatur mengenai keamanan manusia dapat memberikan pengertian secara umum bahwa keamanan manusia sangat penting untuk keamanan internasional dan tatanan internasional yang tidak dapat sepenuhnya bergantung pada kedaulatan dan kelangsungan negara tetapi juga bergantung pada keamanan manusia yang ada didalamnya (Hampson, 2008).

Para pestudi keamanan manusia berpendapat bahwa saat ini memang ancaman-ancaman datang dari dalam suatu negara cenderung menghadirkan konflik internal seperti ancaman penyakit, kelaparan, kontaminasi lingkungan, dan 
kekerasan kriminal. Dan tidak menutup kemungkinan ancaman-ancaman akan lebih besar datang malah bukan dari lingkup eksternal tetapi lingkup internal sehingga keamanan manusia tetap akan menjadi sasaran utama dari keamanan negara yang ideal (NEWMAN, 2010). Salah satu dimensi yang diangkat dalam keamanan manusia adalah ketahanan pangan (Food Security).

Adanya ancaman terkait dengan ketersediaan pangan dalam suatu negara dapat menjadi hal yang krusial sebab dengan adanya krisis pangan, masyarakat dalam suatu negara akan terserang ancaman kelaparan. Kelaparan pada hakikatnya bukan lah semata-mata fenomena natural dari manusia itu sendiri, tetapi karena adanya distribusi dan kelangkaan makanan tentu akan mempengaruhi kebutuhan dasar manusia dan kekerasan akan terjadi dimana-mana. Oleh karena itu ancaman adanya krisis pangan ini dapat mengganggu hak kehidupan masyarakat. Sehingga ancaman kekerasan/konflik internal akan sulit terhindarkan dan ini dapat mengganggu stabilitas keamanan negara. Salah satu contoh yang bisa dilihat adalah krisis politik yang bersamaan dengan adanya krisis ekonomi di Venezuela yang berakibat terhadap krisis pangan dinegara tersebut membuat sebagian masyarakat menggunakan kekerasan sehingga stabilitas keamanan domestik menjadi terganggu.

Tulisan ini bertujuan untuk mendeskripsikan mengenai bagaimana hubungan resiko krisis pangan dalam suatu negara dapat memicu stabilitas keamanan negara seperti 
terjadinya konflik antar masyarakat dalam suatu negara. Metode yang digunakan dalam penulisan ini adalah analisis deskriptif terhadap fenomena krisis pangan yang terjadi di Venezuela yang berhubungan dengan konflik antar masyarakat. Dalam penulisan ini menggunakan perspektif Sekuritisasi Pangan sebagai landasan pembahasan.

\section{The Securitization of Food}

Sebelum membahas konsep sekuritisasi pangan, ada baiknya kita mengetahui terlebih dahulu mengenai pengertian umum konsep sekuritisasi itu sendiri. Sekuritisasi dalam hubungan internasional merupakan (Mazhab Kopenhagen) proses perubahan subjek menjadi persoalan 'keamanan' oleh negara. Ini adalah politisasi versi ekstrem yang mengizinkan cara apapun demi menjaga keamanan. Studi sekuritisasi berusaha memahami "siapa yang melakukan sekuritisasi (pelaku), atas dasar apa (ancaman), untuk siapa (objek acuan), mengapa, bagaimana hasilnya, dan apa saja syaratnya (Buzan \&Wæver, 1998). Sekuritisasi telah menggeser isu-isu keluar dari debat politik 'normal' ke dalam bidang politik yang dianggap darurat dengan menghadirkannya sebagai ancaman eksistensial (Peoples \& Vaughan-Williams, 2010).

Sekuritisasi Pangan (The Securitization of Food) dapat dikaitkan sebagai perluasan umum dari konsep keamanan setelah berakhirnya perang dingin, untuk memasukkan berbagai ancaman 'non-tradisional' dan sebagai pengakuan 
atas pentingnya menempatkan individu dan masyarakat sebagai objek referensi keamanan. Pembingkaian ancaman pangan sebagai isu keamanan memperoleh momentum setelah krisis pangan tahun 2007-2008, ketika kenaikan harga makanan menyebabkan kerusuhan di banyak bagian dunia, mengancam legitimasi dan stabilitas negara-negara bagian. Ketersediaan pangan sebagai bahan pokok dapat menjadi penyokong kehidupan bermasyarakat dalam suatu negara. Ancaman ketersediaan pangan merupakan bentuk atau manifestasi dari ketidakamanan manusia. Hal ini dapat dikatakan bahwa makanan dapat dimanfaatkan sebagai senjata politik oleh negara-negara: dan dalam dunia hubungan internasional, makanan dapat dikarakterisasi sebagai bentuk dan simbol kekuatan politik (Shepherd, 2012).

Keamanan pangan juga memfokuskan kembali perhatian terhadap keamanan pada manusia serta keamanan terhadap sumber pangan yang tidak aman. Ketersediaan pasokan makanan yang cukup dapat menjadi inti dari kontak sosial disemua sistem politik negara. Kemampuan suatu negara untuk memastikan warganya memiliki akses terhadap makanan dan dapat memenuhi kebutuhan energi dan nutrisi merupakan penentu utama legitimasi keberadaan negara tersebut (Teng \& Lassa, 2016). Ketahanan pangan ini dapat digunakan sebagai senjata dan ancaman bagi setiap negara, yang secara tidak langsung berdampak pada sistem keamanan domestik negara. 
Food Security (Ketahanan Pangan)

Definisi Food Security oleh Komite PBB tentang World Food Security dapat diartikan sebagai suatu kondisi dimana semua orang dapat setiap saat memiliki akses fisik, sosial dan ekonomi untuk mengkonsumsi makanan yang cukup aman dan bergizi untuk memenuhi kebutuhan makanan dan preferensi makanan mereka agar dapat hidup aktif dan sehat. Serta memberikan dan menyediakan informasi reguler sehubungan dengan produksi, konsumsi, dan perdagangan produk-produk makanan pokok, (khususnya gandum, beras, sereal sekunder, kacang kedelai dan daging) dan pada aspek lain dapat juga mempengaruhi situasi masyarakat misalnya harga dan produksi sebagai elemen utama dan ketersediaan peralatan pertanian. Selama beberapa dekade memang perubahan iklim, pertumbuhan populasi global, kenaikan harga pangan, dan keadaan lingkungan memiliki dampak yang signifikan dan tentunya berpengaruh terhadap terhadap ketahanan pangan nasional (UN-WFC, 1974). Ketahanan pangan sebagai konsep muncul dipertengahan 1970-an, dalam sebuah diskusi masalah pangan internasional termasuk didalamnya pada saat krisis pangan global.

Pada pertemuan ini, fokus perhatian awalnya terutama pada masalah pasokan dan menjamin ketersediaan pangan sehingga harga kebutuhan makanan pokok dapat stabil ditingkat internasional maupun nasional (Maxwell \& Frankenberger, 1993). Pada tahun 1974 di World Food Summit hadir dengan serangkaian pengaturan dan kelembagaan baru 
yang mencakup informasi, sumber daya untuk mempromosikan keamanan pangan dan forum dialog mengenai isu-isu kebijakan terkait pangan (WFS, 1996). Kelaparan global dan malnutrisi sebagai tema ketahanan pangan telah muncul sebagai keprihatinan bersama untuk beragam kelompok lembaga keuangan dan perdagangan internasional, aktivis hak pangan, organisasi non-pemerintah, dan pemerintah nasional (Schanbacher, 2010). Selain itu World Food Programme (WFP), menganggap manusia dalam keadaan aman ketika persediaan makanan dan akses untuk memiliki persediaan makanan tersebut cukup, aman, bergizi untuk dapat mempertahankan kehidupan yang aktif dan sehat. Para analis, melihat tiga elemen utama dari food security, yaitu:

\begin{tabular}{|l|l|}
\hline $\begin{array}{c}\text { Ketersediaan Makanana } \\
\text { (Food Availability) }\end{array}$ & $\begin{array}{l}\text { Yaitu jumlah persediaan makanan } \\
\text { harus berada dalam jumlah yang } \\
\text { cukup dan berlaku secara konsisten. } \\
\text { Hal ini tentunya di pertimbangkan agar } \\
\text { stok dan produksi di area tertentu } \\
\text { dapat memiliki kapasitas agar dapat } \\
\text { membawa pangan tersebut melalui } \\
\text { jalur perdagangan atau secara } \\
\text { bantuan. }\end{array}$ \\
\hline
\end{tabular}




\begin{tabular}{|c|l|}
\hline $\begin{array}{c}\text { Akses Makanan (Food } \\
\text { Access) }\end{array}$ & $\begin{array}{l}\text { Yaitu masyarakat harus dapat secara } \\
\text { teratur memperoleh makanan dalam } \\
\text { jumlah yang cukup, baik itu melalui } \\
\text { pembelian, produksi rumah, secara } \\
\text { barter, hadiah, pinjaman atau bantuan } \\
\text { pemberian makanan. }\end{array}$ \\
\hline Pemanfaatan Pangan \\
(Food Utilization) & $\begin{array}{l}\text { Yaitu makanan yang dikonsumsi harus } \\
\text { memiliki kandungan nutrisi yang baik } \\
\text { untuk tubuh manusia. Hal ini } \\
\text { termasuk dalam bagaimana cara } \\
\text { memasak, menyimpan dan kebersihan, } \\
\text { kesehatan individu, air dan sanitasi } \\
\text { serta pemberian makanan dalam } \\
\text { praktik kehidupan sehari-hari. }\end{array}$ \\
\hline
\end{tabular}

Dalam konteks ketahanan pangan (Food Security) ini dapat dipahami sebagai kemampuan dasar manusia untuk memenuhi kebutuhan pokok / subsistensi protein dan energi agar berfungsi secara efektif sebagai individu yang sehat (Hyande \& Oboh, 2007). Pada tahun 1986, Bank Dunia mendefinisikan 'keamanan pangan (Food Security)' sebagai "akses bagi semua manusia terhadap makanan yang cukup agar dapat hidup yang aktif dan sehat". Dua elemen penting dalam mengidentifikasi dari ketahanan pangan (Food Security) yaitu sebagai "ketersediaan makanan dan kemampuan untuk memperolehnya" (World Bank, 1986). Ketahanan pangan 'adalah kapasitassetiap masyarakat dan negara untuk memobilisasi makanan yang secara cukup melalui produksi, akuisisi dan distribusi secara berkelanjutan. Ketahanan 
pangan ini bergantung pada sumber daya lahan yang tersedia bagi masyarakat serta kemampuan mereka untuk memobilisasi sumber daya tersebut agar dapat diproduksi atau distribusi guna untuk mencapai kehidupan yang aktif dan sehat, ECA, 2013: 33 (MOHAMMED\&ONWURAH, 2016).

Ketahanan Pangan (Food Security) dan Konflik

Pada tingkat (individu, rumah tangga, nasional, regional dan global), ketahanan pangan akan tercapai jika memiliki akses fisik secara ekonomi terhadap makanan yang cukup, aman dan bergizi agar dapat memenuhi kebutuhan makanan yang baik dan sehat. Hal seperti ini dapat mengidentifikasi akan adanya kebutuhan-kebutuhan makanan yang aman dan bergizi bagi masyarakat sehingga kehidupan dapat berjalan dengan aman dan baik (SCHANBACHER, 2010). Sebagian besar bentuk kekerasan politik, khususnya protes kekerasan, kekerasan terhadap rakyat, dan konflik sipil paling banyak terjadi di negara-negara pada tingkat pembangunan ekonomi yang lebih rendah. Adanya hubungan antara pendapatan per kapita yang rendah, kemiskinan, dan ketidakamanan terhadap pangan dapat menjadi penyebab terjadinya gejolak ekonomi disuatu negara. Hal ini jelas bahwa kekerasan politik sebagian besar adalah fenomena akibat akases terhadap yang tidak aman. Konflik dan protes sipil serta kerusuhan dalam masyarakat dapat terjadi akibat pertumbuhan ekonomi yang tidak baik. Artinya gejolak ekonomi memiliki berkorelasi dengan konflik dalam suatu negara. Dengan memberikan 
bantuan terhadap produksi makanan dan upaya meningkatkan ketahanan pangan, dapat mengurangi gejolak konflik dalam negara dan stabilitas keamanan dapat berjalan dengan baik (Brinkman \& Hendrix, 2010).

Konflik dan ketidakamanan sipil juga dapat mendatangkan bencana pada produksi dan pertumbuhan ekonomi serta dapat mengganggu ketahanan pangan dan gizi. Selain itu juga tentunya akan menghadirkan kesulitan dalam hal kesehatan dan gizi. Selain itu konflik yang dihadirkan ini juga menyebabkan resesi ekonomi yang mendalam, mendorong infasi dan mengikis keuangan fiskal serta mempengaruhi mata pencaharian dan mengganggu kehidupan sosial (UN:FAO, 2007). Selain itu kelangkaan pangan (Food Insecurity) erat kaitannya dengan konflik bersenjata serta perseteruan antar warga sipil, kerusuhan, dan bentuk-bentuk kekerasan politik dan sosial lainnya (Mitchell,et al, 2015).

Pada akhirnya ada risiko yang mempengaruhi stabilitas ketahanan pangan dalam masyarakat. Di tingkat nasional, ini akan meningkatkan permasalahan seperti iklim dan konflik (OECD, 2013). Secara singkat ketahanan pangan ini dapat saling terkait antar satu sama lain dalam aspek negara. Apabila kebutuhan akan makanan tidak tercapai dengan baik maka timbul keresahan dalam masyarakat hingga masyarakat dapat melakukan segala macam cara untuk mencapai kebutuhan akan makanan tersebut sehingga konflik internalpun sulit untuk dihindari dan stabilitas keamanan negara akan menjadi terganggu. 
Krisis Pangan

Secara global fenomena krisis pangan telah memberikan implikasi terhadap

agenda politik nasional maupun transnasional. Hal ini didorong sejak 2007, akibatnya terjadi kenaikan harga pangan, akuisisi lahan pertanian dalam skala besar, serta meningkatnya protes publik. Fenomena ini menimbulkan adanya bantuan pembangunan dan reformasi untuk proses tata kelola global, serta aktivisme yang diperkuat oleh gerakan sosial agraria (Le Billon, et all, 2017). Persediaan pangan dalam suatu negara merupakan jantung dari sistem ekonomi politik. The Food and Agriculture Organization (FAO) melaporkan bahwa 34.000 orang meninggal setiap hari karena kelaparan, dan 930 juta orang menderita kekurangan gizi parah.

Kekurangan pangan selalu berasal dari krisis subsisten atau adanya ketidaksanggupan dalam pemenuhan biaya hidup yang tinggi. Secara universal memang tidak ada yang menghubungkan antara kelangkaan dan pemberontakan tetapi, kehadiran protes-protes keras oleh masyarakat didalam negara terkait pasokan makanan yang tidak cukup dan terjadinya kelaparan yang kronis dapat meningkatkan atensi masyarakat untuk bertindak menggunakan kekerasan. Kelaparan telah lama menyandera manusia. Ketakutan akan fenomena ini merupakan hal yang ditakutkan oleh manusia 
seperti misalnya saja kekurangan bahan-bahan primer (makanan utama) yang akan dikonsumsi.

Fenomena ini membuat ketakutan terhadap individu bahkan terjadi peningkatan keinginan untuk melarikan diri telah menjadi kekuatan pendorong untuk mengeksploitasi sumber daya alam dan mengarah pada pengembangan teknik untuk memperoleh makanan, berburu, memancing, menggembala, dan bertani untuk dapat memproduksi pangan industri (Bruegel, 2011). Kemiskinan telah membuat kelaparan kronis dalam masyarakat untuk berupaya menjaga diri mereka sendiri dari resiko penyebaran penyakit (Devereux, 2009). Penting untuk memahami bagaimana ketiga konsep ini terkait dengan kekurangan pangan:

\begin{tabular}{|c|c|}
\hline Kelaparan & $\begin{array}{l}\text { Dipahami sebagai perasaan yang tidak nyaman } \\
\text { atau menyakitkan yang disebabkan oleh konsumsi } \\
\text { energi makanan yang tidak mencukupi. Secara } \\
\text { ilmiah, kelaparan disebut sebagai perampasan } \\
\text { makanan. Kelaparan atau kekurangan gizi } \\
\text { mengacu pada persediaan yang tidak cukup atau } \\
\text { kekurangan total kalori yang dikonsumsi. Hal ini } \\
\text { tahap yang paling buruk dalam ketahanan } \\
\text { pangan, dimana makanan yang dikonsumsi tidak } \\
\text { mencukupi untuk memenuhi kebutuhan energi } \\
\text { dasar secara berkelanjutan (Pelaez, 2005). }\end{array}$ \\
\hline Malnutrisi & $\begin{array}{l}\text { Terjadi akibat defisiensi, kelebihan atau } \\
\text { ketidakseimbangan dalam mengkonsumsi nutrisi. } \\
\text { Malnutrisi mungkin merupakan hasil dari }\end{array}$ \\
\hline
\end{tabular}




\begin{tabular}{|l|l|}
\hline & $\begin{array}{l}\text { kerawanan pangan, atau mungkin berhubungan } \\
\text { dengan faktor-faktor non-makanan, seperti: } \\
\text { Perawatan yang tidak memadai untuk anak-anak, } \\
\text { Layanan kesehatan yang tidak mencukupi; dan } \\
\text { Lingkungan yang tidak sehat. }\end{array}$ \\
\hline Kemiskinan & $\begin{array}{l}\text { Kemiskinan sebagai penyebab kelaparan. Adanya } \\
\text { kurangnya nutrisi yang dikonsumsi merupakan } \\
\text { penyebab utama dari kemiskinan. "Kemiskinan } \\
\text { mencakup adanya kekurangan diberbagai dimensi } \\
\text { yang terkait dengan kemampuan manusia dalam } \\
\text { memenuhi kebutuhannya seperti konsumsi } \\
\text { terhadap makanan, kesehatan, pendidikan, hak, } \\
\text { suara, keamanan, martabat, dan pekerjaan yang } \\
\text { layak. (OECD) (FAO: FAO Security Programme, } \\
\text { 2008). }\end{array}$ \\
\hline
\end{tabular}

Kelaparan, kekurangan gizi serta kemiskinan saling terkait erat antar satu sama lain. Kemiskinan sekarang umumnya dianggap sebagai akar penyebab kelaparan dan kekurangan gizi. Namun, yang tidak dipahami adalah bahwa kelaparan dan malnutrisi dapat juga menjadi penyebab utama kemiskinan yang tentu saja dpat berkontribusi pada ketidakstabilan sosial dan politik(FAO/IFAD/WFP,2002). Di sejumlah pertemuan internasional, komunitas internasional telah mengakui keamanan pangan sebagai salah satu hak asasi manusia yang paling mendasar (Shaw, 2007). 
Hubungan Ketahanan Pangan Dan Stabilitas Keamanan Negara

Permasalahan kekurangan pasokan makanan dalam suatu negara dapat mengakibatkan kelaparan di mana-mana. Permasalahan ketahanan pangan ini dapat menjadi ancaman bagi individu didalamnya dan juga dapat mengganggu stabilitas keamanan dalam negara tersebut. Dalam permasalahan ketahanan pangan ini erat kaitannya dengan beberapa aspek salah satunya adalah perubahan iklim dalam suatu negara. Hadirnya konsekuensi konflik dan bencana alam yang terkait dengan iklim yang buruk dalam suatu negara dapat memperbesar masalah ketahanan pangan, gizi, dan juga dapat berlanjut kearah hadirnya konflik dan krisis yang berkepanjangan (UN: FAO, 2007). Dengan hal ini dapat dilihat bahwa apabila terjadi kekurangan pangan dalam suatu negara dapat terkait dengan segala aspek dan ini tidak menutup kemungkinan dapat menimbulkan berbagai konsekuensi-konsekuensi konflik yang akan berpengaruh pada stabilitas keamanan dalam negara itu sendiri.

Dinamika Stabilitas Politik, Keamanan dan Krisis Pangan di Venezuela

Pada tahun 1986, Laporan World Bank telah memberi pengaruh terhadap "Kemiskinan dan Kelaparan yang berfokus pada dinamika sementara dari ancaman ketidakamanan pangan. Bencana alam, krisis ekonomi dan konflik dapat dikaitkan dengan permasalahan kemiskinan yang 
berkelanjutan/struktural serta pendapatan masyarakat yang rendah. Konsep ketahanan pangan ini dapat dijabarkan dalam hal: "Akses semua manusia terhadap makanan yang cukup agar dapat hidup yang aktif dan sehat" (Mohammed\&Onwurah, 2016).

Pada tahun 2002 hingga 2008 pemerintah di Amerika Selatan dilanda krisis ekonomi. Dan pada tahun 2008, ledakan komoditas primer ini gagal, terjebak dalam pusaran krisis keuangan saat ini. Pemerintah Amerika Latin lainnya tidak begitu cepat menanggapi dampak krisis terhadap ekonomi regional dan lokal, meskipun banyak tanggapan dari berbagai kalangan (Veltmeyer,2010).

Salah satu yang negara bagian Amerika Latin yang sedang mengalami krisis ekonomi adalah Venezuela. Tetapi sebelum adanya krisis ekonomi besar-besaran di tahun 2008, Venezuela memang sudah mengalami krisis ekonomi jauh sebelumnya. Venezuela mengalami krisis ekonomi yang mendalam selama tahun 1980-an dan 1990-an. Kondisi krisis termasuk hiperinflasi, tingkat pertumbuhan ekonomi negatif, dan tingkat kemiskinan yang meningkat. Tantangan Venezuela termasuk tingkat pertumbuhan ekonomi negatif dan beberapa inflasi.Kesulitan ekonomi Venezuela selama tahun 1980-an dan 1990-an berakar pada keputusan politik dan ekonomi yang dibuat selama tahun 1970-an dan sebelumnya. Mungkin periode yang paling penting adalah Presidensi Aksi Demokrat Carlos Andrés Pérez dari 1974 hingga 1979. Pérez secara signifikan meningkatkan 
perlindungan tarif barang-barang konsumsi dan memberikan subsidi yang luas kepada industri-industri yang disukai (Seawright, 2012).

Stabilitas politik yang tidak baik juga ikut mendukung terjadinya kondisi ekonomi yang buruk di Venezuela. Sejak 12 Februari 2014, demonstrasi populer yang mendukung dan menentang pemerintah telah berlangsung di Venezuela. Protes dimulai sebagai ekspresi mahasiswa tetapi mereka dengan cepat diambil oleh oposisi yang berusaha menyalurkan ketidakpuasan umum masyarakat dengan biaya hidup dan ketidakamanan yang tinggi. Dalam beberapa kasus, kekerasan terjadi atas peristiwa-peristiwa ini (Lockhart,2014).

Pada pemerintah Nicolas Maduro voting dilakukan untuk keperluan pendirian lembaga legislatif yang berisikan para pendukungnya. Kejadian ini menimbulkan unjuk rasa masyarakat setempat sehingga stabilitas politik menjadi buruk, bersamaan dengan itu krisis ekonomi melanda negara ini sehingga krisis pangan tak terhindarkan kehadirannya.Banyak negara berkembang terus menderita kerawanan pangan kronis dan tingginya tingkat kekurangan gizi dan berada di bawah ancaman konstan kelaparan yang disebabkan oleh krisis ekonomi dan bencana alam (Prabu \& Sanyal,2009). Sehingga memicu adanya krisis pangan disuatu negara. Krisis pangan ini berakibat terhadap kesejahteraan masyarakat bahkan berujung terhadap tingkat konflik dan kekerasan yang meningkat. Krisis pangan ini tidak lain diakibatkan adanya pemasokan utama ekonomi negara 
mengalami penurunan selain itu karena sistem ekonomi yang mengalami penurunan ini menyebabkan pemerintah kewalahan dalam mengurus masyarakatnya sehingga akibatnya masyarakat dalam suatu negara mengalami kelangkaan makanan atau kelaparan.

Beberapa faktor yang mengakibatkan suatu negara mengalami krisis pangan hebat antara lain kelebihan penduduk, distribusi makanan, akses ke tanah dan kredit, diskriminasi terhadap perempuan, korupsi, perang,utang luar negeri, kemiskinan, perkembangan dalam bioteknologi, dan perdagangan dunia (Pelaez, 2005). Krisis pangan yang terjadi di Venezuela memang berakar dari stabilitas politik yang tidak kondusif dinegara ini tetapi krisis ekonomi datang secara bersamaan seperti terjadinya krisis pangan yang diakibat harga minyak bumi yang terus turun, menyebabkan inflasi melonjak dan masalah korupsi. Beberapa negara menolak terhadap voting tersebut salah satunya Amerika Serikat, sehingga AS menjatuhkan sanksi ekonomi bagi industri minyak Venezuela. Venezuela memiliki cadangan minyak dunia dan minyak ini juga menjadi satu sumber pendapatan negara tersebut. Dengan adanya sanksi ini kondisi kekurangan pangan di Venezuela semakin buruk yang di karenakan sedikitnya cadangan devisa negara untuk impor pangan. Dengan adanya krisis pangan ini, masyarakat Venezuela melakukan berbagai cara untuk tetap terpenuhinya konsumsi terhadap makanan. Venezuela tengah menghadapi gejolak ekonomi dan politik. Inflasi tahun 2017 melampaui 
2.600 persen, menurut anggota parlemen oposisi, yang telah memperburuk kekurangan makanan dan obat-obatan. Pada saat ini, Venezuela diperintah oleh Majelis Konstituante, terdiri dari sekutu dekat Presiden Nicolás Maduro. Kongres yang dikuasai oposisi telah dikesampingkan, pengadilan tertinggi ditumpuk dengan loyalis Maduro, dan penjaga nasional telah diperintahkan untuk mengambil garis keras terhadap setiap protes yang dilakukakan oleh masyarakat setempat (Daniels, 2018). Laporan berita BBC, bahwa masyarakat di negara ini telah mengemis makanan untuk bertahan hidup. Krisis ekonomi di Venezuela semakin memburuk. Rakyat kini semakin kekurangan makanan karena negara membatasi impor pangan, sementara inflasi membuat harga bahan pokok melonjak drastis (BBC, 2018).

Bahkan beberapa masyarakatnya memilih untuk melakukan eksodus ke negara tetangga. Sebab Venezuela sedang menghadapi stabilitas keamanan negara yang buruk. Dengan hadirnya masalah krisis pangan ini membuat masyarakat semakin meningkatkan kekerasan guna untuk mendapatkan pasokan makanan. Beberapa masyarakat melakukan aksi penjajahan makanan yang menimbulkan aksi kekerasan antar warga. Selain itu aksi pencaharian berbagai sumber sehingga dapat ditukarkan untuk membeli makanan sedang dilakukan banyak warga venezuela. Penjarahan dan kericuhan karena kekurangan makanan mulai sering terjadi secara sporadis di seluruh negeri. Krisis pangan semakin terasa menghantam Venezuela dalam beberapa pekan 
terakhir. Penduduk yang frustasi berteriak menginginkan makanan dalam unjuk rasa. Tak jarang terjadi perkelahian di toko-toko yang menjual makanan (Internasioanl Republika, 2016).

Kesimpulan

Sistem politik dan krisis ekonomi dapat menyebabkan gejolak dalam masyarakat sehingga stabilitas kemanan negara menjadi terganggu. Krisis ekonomi dalam suatu negara telah memberikan dampak yang cukup signifikan terhadap perkembangan negara. salah satu krisis ekonomi yang sangat ditakutkan oleh sebagian besar negara adalah terjadinya krisi pangan. Adanya kekurangan terhadap akses makanan dapat menciptakan ancaman kelaparan,kekurangan nutrisi, konflik antar warga, bahkan kematian. Venezuela tengah menghadapi krisis ekonomi yang datang bersamaan dengan stabilitas politik yang buruk. Akibatnya masyarakat Venezuela mengalami gejolak antar pemerintah dan masyarakat. Venezuela dikenal sebagai negara pengahasil minyak dunia. Penghasilan minyak ini merupakan salah satu penghasilan negara, tetapi karena jatuhnya harga minyak dunia maka sistem penerimaan negara menjadi terganggu. Akibatnya negara mengalami krisis ekonomi. ancaman kekurangan pangan menjadi hal yang menakutkan dalam beberapa negara.

Venezuela tengah menghadapi ancaman kekurangan pangan yang mengakibatkan banyak masyarakat menjadi 
terserang kelaparan. Untuk memperoleh akses makanan, beberapa masyarakat melakukan penjarahan terhadap makanan dan terjadinya konflik perkelahian antar masyarakat membuat stabilitas keamanan negara menjadi terganggu. Oleh karena itu, ketahanan pangan dapat berhubungan dengan berbagai aspek dalam negara dan ini dapat bertujuan terhadap stabilitas keamanan negara.

\section{Referensi}

Beeson, M \& Bisley, N 2017, World Politics: issues in 21st century,3rd edn, PALGRAVE, London.

Buzan,B, Wæver,O \& Wilde,JD 1998, Security: A New Framework for Analysis, Boulder: Lynne Rienner Publishers, London.

Brinkman, H. and C. Hendrix 2010, Food Insecurity and Conflict: Applying the WDR Framework in World Development Report 2011, Texas, pp.4-6

Bruegel, M, 2011, Investigation: From the Crisis of Food to Food in Crisis, gastronomica: the journal of food and culture, vol.11, no.3, pp.40-52, issn 1529 3262. (C) 2011 by the regents of the university of california.

<http://www.ucpressjournals.com/reprintinfo.asp.doi:10.152 5/gfc.2011.11.3.

Daniels, JP 2018, In Colombia Border Town Desperate Venezuelans Sell Hair To Survive, Media Release, 17 Februari, $<$ https://www.nytimes.com/2018/02/17/world/ameri cas/venezuela-crisis colombiamigration.html?action=click\&contentCollection $=$ Americas \&module $=$ RelatedCoverage\&region $=$ EndOfArt icle\&pgtype $=$ article $>$ 
Devereux, S, 2009, 'Seasonality and social protection in Africa' ,Growth \& Social Protection Working Paper 07, Future Agricultures/Centre for Social Protection, Brighton, pp.7.

FAO-Food Security Programme 2008, Food Security Information for Action Practical Guides "An Introduction to the Basic, <www.foodsec.org/docs/concepts_guide.pdf>

FAO (Food and Agriculture Organization of the United Nations) 1974, COMMUNICATION FROM THE COMMISSION TO THE COUNCIL WORLD FOOD CONFRENCE, Rome 5-16 November. Brussels.

FAO, IFAD, UNICEF, WFP and WHO 2017. The State of Food Security and Nutrition in the World 2017.Building resilience for peace and food security. Rome, FAO.

FAO UN 2007, Conflict, Food Security and Nutrition : The Imperative Of Sustainable Peace, in "THE STATE OF FOOD SECURITY AND NUTRITION IN THE WORLD”.

Gonzalez-Pelaez, A 2005, Rights and World Trade: Hunger in international society, Routledge, New York.

Hampson, FO 2008, Human Security, in Williams PD, Security Studies: an introduction, Routlegde, New York, pp.232.

Hyande, A.A. and Oboh V.U. 2007, The imperative of "plan budget link" coordination for food security and sustainable development in democratic setting in the 21st century in National Association of Science, Humanities and Education Research. Vol. 5, No. 1, 191197.

Le Billon, P, Sommerville,M\& Essesx, J Jamey Essex 2014, Introduction: Global Food Crisis, Geopolitics, 19:2. Pp. 235-238 
Maxwell \& Frankenberger, TR, eds. 1993, Household Food Security: Concepts, Indicators, Measurements: A Technical Review, UNICEF and IFAD, New York and Rome.

Michell, D, Hudson, D, Post, R, Bell, P, \& Williams, R,B , Food Security and Conflict" In Food Security in an UncertainWorld. Published online.pp 211-225, viewed 16 Dec 2015, <http://dx.doi.org/10.1108/S1574871520150000015022

MOHAMMED, NT \& ONWURAH, CP 2016, A POLITICAL ECONOMY ANALYSIS ON SMALL SCALE FARMERS AND FOOD SECURITY IN NIGERIA in European Journal of Business and Social Sciences, Vol. 5, No. 04, pp. 3549, viewed 4 July 2016, <http://www.ejbss.com/recent.aspx-/>

NEWMAN E, 2010 "Critical human security studies" British International Studies Association" Review of International Studies, 36, 77-94.

OECD 2013, Global Food Security: Challenges for the Food and Agricultural System, OECD Publishing.

Peoples, C \&Williams,NV 2010, Critical Security Studies: an Introduction, Routledge, London and New York.

SCHANBACHER, WD 2010, The Politics of Food The Global Conflict between Food Security and Food Sovereignty"PRAEGER, California.

Seawright, J 2012, -SYSTEM COLLAPSE : The Roots of Crisis in Peru and Venezuela, Stanford University Press, California.

Shaw,JD 2007, World Food Security: A History since 1945, PALGRAVE MACMILLAN, New York.

Shepherd, B. 2012, Thingking critically about food security, Security Dialogue, 43(3): 195-212 
Veltmeyer, H 2010, The Global Crisis and Latin America in Globalizations, Vol. 7, Nos. 1-2, pp. 217-233, viewd March-June 2010, http://www.tandfonline.com/loi/rglo20.

Teng,P\& Lassa,J 2016, Food Security, in Anthony MC, An Introduction Non-Traditional Security Studies A Transnational Approach, Sage, London, pp.115.

UNDP (United Nation Development Programme) 1994, HUMAN DEVELOPMENT REPORT 1994, Oxford University Press, New York

Venezuela tangkap 400 orang terkait penjarahan, Viewed 16 Juni $2016 \quad$ 19:02 WIB, $<$ http://internasional.republika.co.id/berita/internasio nal/global/16/06/16/o8v5fo-venezuela-tangkap-400orang-terkait-penjarahan $>$.

Krisis Venezuela: Mengemis makanan untuk bertahan hidup ,Viewed 23 Februari 2018, <http://www.bbc.com/indonesia/media-43168864>

WFO, What is food security, World Food Programme. 